ARTICLE

https://doi.org/10.1038/s41467-019-13945-1

\title{
Boosting fast energy storage by synergistic engineering of carbon and deficiency
}

Shengjue Deng ${ }^{1,9}$, He Zhu ${ }^{2,9}$, Guizhen Wang 3,9, Mi Luo ${ }^{4}$, Shenghui Shen ${ }^{1}$, Changzhi Ai ${ }^{3}$, Liang Yang ${ }^{3}$,

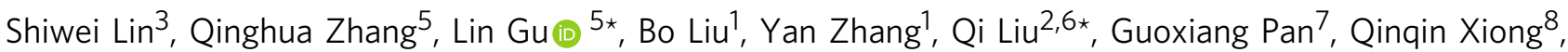
Xiuli Wang ${ }^{1}$, Xinhui Xia (i) ${ }^{1 \star} \&$ Jiangping $T u^{1}$

Exploring advanced battery materials with fast charging/discharging capability is of great significance to the development of modern electric transportation. Herein we report a powerful synergistic engineering of carbon and deficiency to construct high-quality three/ two-dimensional cross-linked $\mathrm{Ti}_{2} \mathrm{Nb}_{10} \mathrm{O}_{29-x} @ \mathrm{C}$ composites at primary grain level with conformal and thickness-adjustable boundary carbon. Such exquisite boundary architecture is demonstrated to be capable of regulating the mechanical stress and concentration of oxygen deficiency for desired performance. Consequently, significantly improved electronic conductivity and enlarged lithium ion diffusion path, shortened activation process and better structural stability are realized in the designed $\mathrm{Ti}_{2} \mathrm{Nb}_{10} \mathrm{O}_{29-x} @ \mathrm{C}$ composites. The optimized $\mathrm{Ti}_{2} \mathrm{Nb}_{10} \mathrm{O}_{29-x} @ \mathrm{C}$ composite electrode shows fast charging/discharging capability with a high capacity of $197 \mathrm{mAhg}^{-1}$ at $20 \mathrm{C}(\sim 3 \mathrm{~min})$ and excellent long-term durability with $98.7 \%$ electron and Li capacity retention over 500 cycles. Most importantly, the greatest applicability of our approach has been demonstrated by various other metal oxides, with tunable morphology, structure and composition.

\footnotetext{
${ }^{1}$ State Key Laboratory of Silicon Materials, Key Laboratory of Advanced Materials and Applications for Batteries of Zhejiang Province, and School of Materials Science \& Engineering, Zhejiang University, Hangzhou 310027, PR China. ${ }^{2}$ Department of Physics, City University of Hong Kong, Hong Kong 999077, PR China. ${ }^{3}$ State Key Laboratory of Marine Resource Utilization in South China Sea, Hainan University, Haikou 570228, PR China. ${ }^{4}$ Shanghai Synchrotron Radiation Facility, Shanghai Institute of Applied Physics, Chinese Academy of Sciences, Shanghai 201210, PR China. ${ }^{5}$ Institute of Physics, Chinese Academy of Sciences, Beijing 100190, PR China. ${ }^{6}$ Shenzhen Research Institute, City University of Hong Kong, Shenzhen 518057, PR China. ${ }^{7}$ Department of Materials Chemistry, Huzhou University, Huzhou 313000, PR China. ${ }^{8}$ College of Materials and Environmental Engineering, Hangzhou Dianzi University, Hangzhou 310018 Zhejiang, PR China. ${ }^{9}$ These authors contributed equally: Shengjue Deng, He Zhu, Guizhen Wang *email: I.gu@iphy.ac.cn; qiliu63@cityu.edu.hk; helloxxh@zju.edu.cn
} 
$\mathrm{n}$ today's society, lithium ion batteries (LIBs) are continuing to boom to meet the growing demand of smart electronics (i.e., smartphones, laptops, etc.) and electric vehicles (EVs) ${ }^{1,2}$. With sales rising of EVs and demand for smartphones slowing, it is reasonable to believe that EVs will dominate the demand for LIBs in the near future. For a decade, with the adoption of high-energy electrode materials, LIB technology is developing rapidly and new EV models are being rolled out with much improved mileage range. However, compared with mileage range, charging time in a few minutes, rather than hours, has already become the major concern in the EV industry. Apparently, exploring high-power electrode materials with fast charge/discharge capability is highly desirable to alleviate this technological challenge and enable the development of new power-intensive devices ${ }^{3-6}$.

The high-speed storage of electrical energy critically depends on the facile transport of $\mathrm{Li}$ ions and electrons in the electrode materials, for which the improvement of the lithium mobility and electronic conductivity is the key of success. Currently, various techniques and approaches have been developed in order to achieve the high-rate electrodes. Among them, the strategy of building nanostructured materials is the most direct and effective one, because the increased surface area can provide more active sites in contact with electrolyte, and the reduced length of diffusion path also fastens the transport of electron and $\mathrm{Li}^{+7-9}$. However, this strategy alone still makes it difficult for the electrode materials to perform well because most battery electrodes have intrinsically low electrical conductivity. In such a context, another important approach, carbon coating, has also been frequently used in both bulk and nanostructured electrodes to optimize the power capability. To date, numerous carbon-coated electrodes, such as $\mathrm{LiFePO}_{4} / \mathrm{C}^{10}$ and $\mathrm{Si} / \mathrm{C}^{11}$, have been developed via various technologies including atomic layer deposition (ALD) ${ }^{12}$, molecular layer deposition (MLD) ${ }^{13}$, hydrothermal ${ }^{14}$, electrodeposition ${ }^{15}$, and chemical vapor deposition ${ }^{16,17}$. Despite the substantial efforts, however, these carbon-coating techniques are still far away from the requirements of industry for their drawbacks, such as high cost and complex synthetic control. For example, ALD and MLD methods fabricate carbon shell from converting organic polyamide film, which usually involves high-temperature treatment $\left(>600^{\circ} \mathrm{C}\right)$ and long-time operation. In addition, such uneconomical process has also been frequently used in other carboncoating techniques like hydrothermal and electrochemical depositions. Furthermore, previous studies have been mainly focused on the uniform carbon coating at the secondary-particle level, which can only take effect on the enhancement of intrinsic conductivity and alleviation of mechanical stress with varying degree of success. Considering the power capability of LIBs depends extremely on the enhanced intrinsic conductivity of every individual grain, carbon coating at the primary-grain level will inherently result in the reinforced rate capability. Given all that, it is highly desirable to fully take advantages of both nanostructuring and carbon-coating techniques. And meanwhile to develop a facile and practical strategy, which can realize boundary carbon coating, which means that the carbon can coat on the active materials at primary-grain level with good conformity and adjustable thickness.

In this work, a facile and controllable low-temperature carboncoating technique has been developed by controlling acetylene decomposition process. In a departure from other approaches, our strategy is capable of creating a uniform carbon coating with desired thickness at primary-grain level, which inherently results in high charge and discharge rate in the nanostructured electrode. As an instance, we demonstrate that with this appropriate low-temperature treatment, the conductive carbon with tunable thickness can be uniformly coated on boundary of nanostructured $\mathrm{Ti}_{2} \mathrm{Nb}_{10} \mathrm{O}_{29}$ (TNO), allowing the rationally designed $\mathrm{Ti}_{2} \mathrm{Nb}_{10} \mathrm{O}_{29-x} @ \mathrm{C}$
( $\left.\mathrm{TNO}_{-x} @ \mathrm{C}\right)$ composites to be used at extremely high rates (197 $\mathrm{mA} \mathrm{h} \mathrm{g}^{-1}$ at $20 \mathrm{C}$, corresponding to a charge time of $3 \mathrm{~min}$ ). Compared with the pure TNO, the significantly improved performance can be ascribed to the enhanced electronic conductivity, improved $\mathrm{Li}$ ion diffusion properties and unexpected defective chemistry. Also, our in situ high-energy synchrotron X-ray diffraction (HEXRD) results show that the lattice anisotropy of TNO ${ }_{-x} @ \mathrm{C}$ has also been significantly weakened during the operation. Importantly, we further demonstrate the generality of this uniform engineering of carbon, which can be applied to achieve other high-rate metal oxides such as $\mathrm{Nb}_{2} \mathrm{O}_{5-x} @ \mathrm{C}$ microrods, $\mathrm{TiO}_{2-x} @ \mathrm{C}$ nanoparticles and $\mathrm{ZnO}_{-x} @ \mathrm{C}$ nanorods.

\section{Results}

Synthesis and structural characterization of the products. As shown in Supplementary Fig. 1-2, puffed rice carbon (PRC) was employed as sacrificial template to obtain three dimensional (3D) hierarchical porous TNO network. A 3D hierarchical microcellular porous morphology was observed for the PRC, which consisted of interconnected secondary carbon sheets ${ }^{18}$. After solvothermal process and annealing in air, the sacrificial PRC template was decomposed and left a 3D hierarchical porous TNO network composed of cross-linked secondary nanosheets and tertiary nanoparticles with an average grain size of $50 \mathrm{~nm}$ and pore size of 10-50 nm (Supplementary Fig. 3). Followed by the controllable acetylene decomposition, the TNO primary grains were uniformly coated with carbon shells, forming 3D hierarchical porous $\mathrm{Ti}_{2} \mathrm{Nb}_{10} \mathrm{O}_{29-x} @ \mathrm{C}\left(\mathrm{TNO}_{-x} @ \mathrm{C}\right)$ composites. The thickness of the boundary carbon could be controlled by the reaction temperature. In our case, three kinds of carbon thicknesses $\left(1 \mathrm{~nm}-350{ }^{\circ} \mathrm{C} ; 3 \mathrm{~nm}-400{ }^{\circ} \mathrm{C} ; 5 \mathrm{~nm}-450{ }^{\circ} \mathrm{C}\right)$ were realized in the $\mathrm{TNO}_{-x} @ \mathrm{C}$ composites and referred as $\mathrm{TNO}_{-x} @ \mathrm{C}_{1}$, $\mathrm{TNO}_{-x} @ \mathrm{C}_{3}$, and $\mathrm{TNO}_{-x} @ \mathrm{C}_{5}$, respectively (Fig. 1a-c and Supplementary Fig. 4). Note that the porous architectures are still well preserved in all the $\mathrm{TNO}_{-x} @ \mathrm{C}$ composites, indicating that the boundary-coated carbon from the acetylene decomposition makes no contribution to the overall morphology.

The microstructure evolutions of the products at different stages were investigated by transmission electron microscope (TEM). Consistent with the scanning electron microscope (SEM) results, the pure porous TNO nanosheets are composed of interconnected TNO nanograins of $50-60 \mathrm{~nm}$ with pore size of $10-50 \mathrm{~nm}$ (Supplementary Fig. 5a-b). The as-prepared TNO nanosheets are highly crystalline, as revealed by the high-resolution TEM (HRTEM) images (Supplementary Fig. 5c) as well as the selected area electron diffraction (SAED, Supplementary Fig. 5c inset) pattern. After controllable acetylene decomposition, interestingly, each primary TNO grain was homogeneously decorated with highquality carbon layer with a thickness of $\sim 3 \mathrm{~nm}$ produced at $400^{\circ} \mathrm{C}$ (Fig. 1d-f). Similarly, uniform carbon coating was also achieved in the $\mathrm{TNO}_{-x} @ \mathrm{C}_{1}$ and $\mathrm{TNO}_{-x} @ \mathrm{C}_{5}$ composites (Supplementary Fig. 5d-i). In the light of similar morphology, the $\mathrm{TNO}_{-x} @ \mathrm{C}_{3}$ composites are selected for the further discussion. The fine microstructure of $\mathrm{TNO}_{-x} @ \mathrm{C}_{3}$ composites was investigated using scanning TEM (STEM) equipped with high-angle annular darkfield (HAADF) and annular bright-field (ABF) detectors. In the HAADF images (Fig. 1g, h), the atomic arrangements are represented with bright spots, in which the $\mathrm{Ti} / \mathrm{Nb}$ sites are much brighter than the $\mathrm{O}$ sites due to the stronger scattering capability of electrons for high- $Z$ atoms. Interplanar $d$-spacings of $18.8 \AA$ and $15.7 \AA$ corresponding to (001) and (100) planes are observed, demonstrating the presence of monoclinal $\mathrm{Ti}_{2} \mathrm{Nb}_{10} \mathrm{O}_{29}$ phase (JCPDS 72-0159) (Fig. 1g, h) $3,19,20$. It is known that the contrast of ABF image is highly sensitive to the light elements like O. Faint dark spots are visible at the $\mathrm{O}$ sites with fluctuant contrast, which 

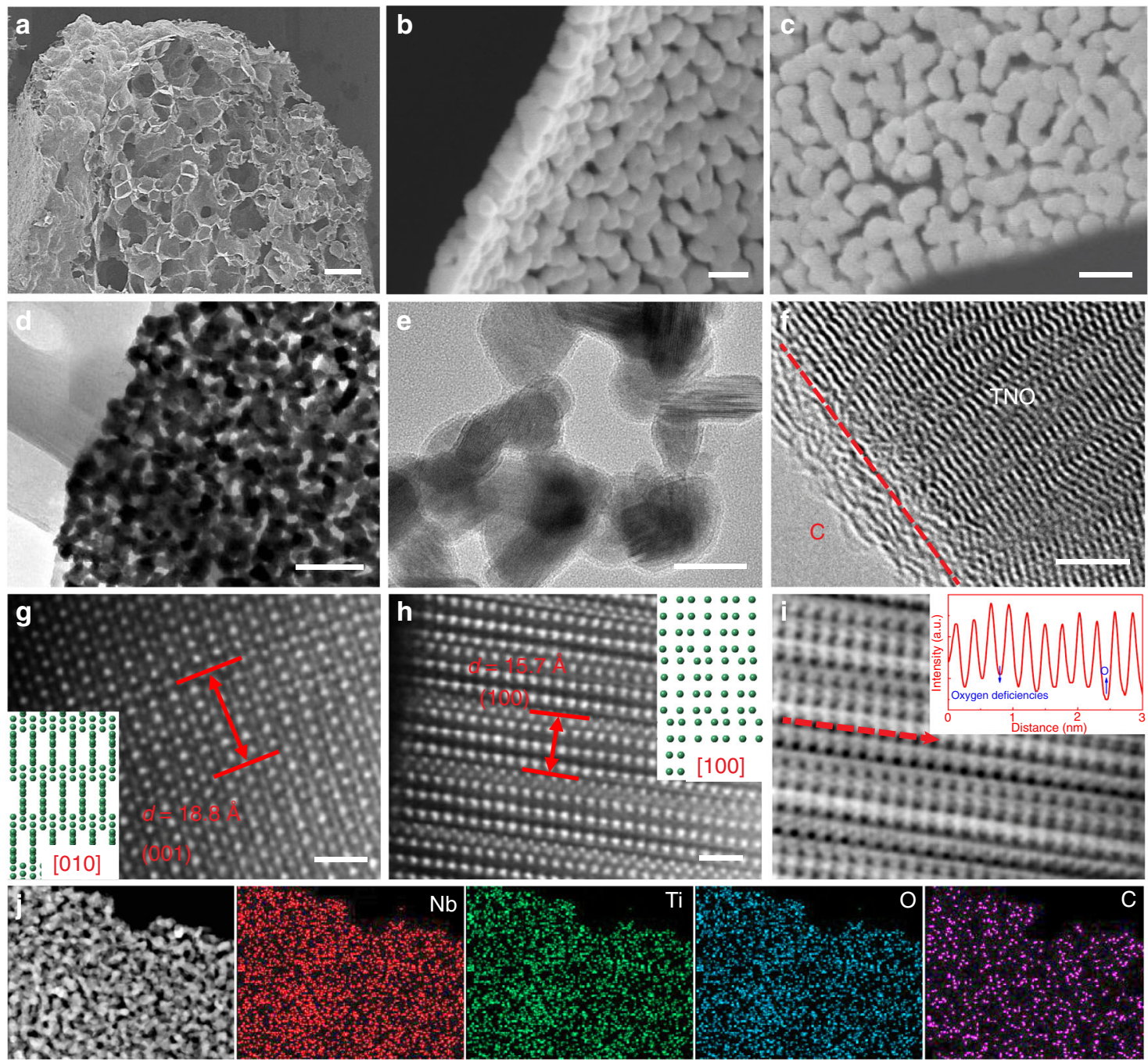

Fig. 1 Synthesis and characterization of all products. a SEM images of hierarchical porous $\mathrm{TNO}_{-x} @ \mathrm{C}_{3}$. b TNO $\mathrm{TN}_{-x} @ \mathrm{C}_{3}$ nanosheets. c TNO $\mathrm{T}_{-x} @ \mathrm{C}_{3}$ from top view.dTEM images of TNO ${ }_{-x} @ C_{3}$. e TEM images of TNO ${ }_{-x} @ C_{3}$. $\mathbf{f H R T E M}$ images of TNO ${ }_{-x} @ C_{3} . \mathbf{g}$ HAADF images of TNO $-x @ C_{3}$. $\mathbf{h} H A A D F$ images of $\mathrm{TNO}_{-x} @ \mathrm{C}_{3}$. i ABF images of TNO $-x @ C_{3}$. j EDS elemental mapping images of Nb, Ti, O, and $\mathrm{C}$ in the TNO $\mathrm{T}_{-x} @ \mathrm{C}_{3}$ composite. Scale bars: a 200 $\mu \mathrm{m}$, b, c $100 \mathrm{~nm}, \mathbf{d} 200 \mathrm{~nm}, \mathbf{e} 50 \mathrm{~nm}, \mathbf{f} 5 \mathrm{~nm}$, and $\mathbf{g}, \mathbf{h} 1 \mathrm{~nm}$.

was revealed by the inconsistent peak valley of the line profile (Fig. 1i). In addition, the weakening of the oxygen contrast firmly proves the abundant oxygen vacancies in the $\mathrm{TNO}_{-x} @ \mathrm{C}_{3}{ }^{21}$. The introduction of the oxygen vacancies at $\mathrm{TNO}_{-x}$ could be due to the reduction of TNO by $\mathrm{H}_{2}$, which is generated from the decomposition of acetylene $\left(\mathrm{C}_{2} \mathrm{H}_{2}\right): \mathrm{C}_{2} \mathrm{H}_{2}=2 \mathrm{C}+\mathrm{H}_{2}$. In other words, the acetylene plays two important roles in the formation of $\mathrm{TNO}_{-x} @ \mathrm{C}_{3}$ composites. On the one hand, the acetylene acts as the boundary carbon source, which deposits outside the primary grains of TNO during the decomposition process. On the other hand, the concomitant $\mathrm{H}_{2}$ could reduce TNO to produce the oxygen vacancy resulting in defective $\mathrm{TNO}_{-x}$. Such dual effects arising from the acetylene decomposition is unique and cannot be realized by the previous carbon-coating technologies. The uniformity of $\mathrm{TNO}_{-} @ \mathrm{C}_{3}$ was also verified by energy dispersive spectrometer (EDS) mapping. The elements of $\mathrm{Ti}, \mathrm{Nb}, \mathrm{O}$, and $\mathrm{C}$ homogeneously distribute in the $\mathrm{TNO}_{-x} @ \mathrm{C}_{3}$ sample (Fig. 1j), indicating the successful synthesis of $\mathrm{TNO}_{-x} @ \mathrm{C}_{3}$ composites. It is noteworthy that our developed synergistic engineering of carbon and deficiency can be highly applicable to other metal oxides with tunable morphology, composition, and structure including $\mathrm{TNO}_{-x} @ \mathrm{C}$ microspheres (Supplementary Fig. 6-7), $\mathrm{Nb}_{2} \mathrm{O}_{5-x} @ \mathrm{C}$ microrods, $\mathrm{TiO}_{2-x} @ \mathrm{C}$ nanoparticles, and $\mathrm{ZnO}_{-x} @ \mathrm{C}$ nanorods (Supplementary
Fig. 8). In a nutshell, the newly developed engineering of carbon and deficiency is a powerful method to simultaneously implement the conformal coating of boundary carbon layer and introduction of abundant oxygen deficiencies in various metal oxides. The phase evolution was monitored by X-ray diffraction (XRD) tests (Fig. 2a and Supplementary Fig. 9a). The diffraction peaks of all the samples could be well indexed to the $\mathrm{Ti}_{2} \mathrm{Nb}_{10} \mathrm{O}_{29}$ phase (JCPDS 72-0159) ${ }^{22}$, suggesting that the coating of boundary carbon does not affect the phase purity of TNO. Raman measurements were conducted to confirm the existence of the carbon-coating layer (Fig. $2 \mathrm{~b}$ and Supplementary Fig. 9b). For the pure unmodified TNO nanosheets, the characteristic peaks at $264,649,894$, and $1003 \mathrm{~cm}^{-1}$ are clearly recognized, matching well with the $\mathrm{Ti}_{2} \mathrm{Nb}_{10} \mathrm{O}_{29}$ phase. As for the $\mathrm{TNO}_{-x} @ \mathrm{C}_{3}$ sample, apart from the above characteristic peaks of TNO, two newly emerged Raman peaks at $1352 \mathrm{~cm}^{-1}$ (disorder induced D-band) and $1585 \mathrm{~cm}^{-1}$ (a graphitic G-band) are detected and the intensity ratio of G-band to D-band $\left(I_{\mathrm{G}} / I_{\mathrm{D}}\right)$ was about 1.30 , suggesting the existence of carbon layer and its high crystallinity. Moreover, the $I_{\mathrm{G}} / I_{\mathrm{D}}$ ratio of $\mathrm{TNO}_{-x} @ \mathrm{C}_{3}$ sample was higher than those of $\mathrm{TNO}_{-x} @ \mathrm{C}_{1}$ and $\mathrm{TNO}_{-x} @ \mathrm{C}_{5}$ samples, indicating the optimal crystallinity of carbon in the $\mathrm{TNO}_{-x} @ \mathrm{C}_{3}$ sample. Thermogravimetric (TG) analysis (Supplementary Fig. 9c) demonstrates that the contents of carbon in the $\mathrm{TNO}_{-x} @ \mathrm{C}_{1}, \mathrm{TNO}_{-x} @ \mathrm{C}_{3}$, 

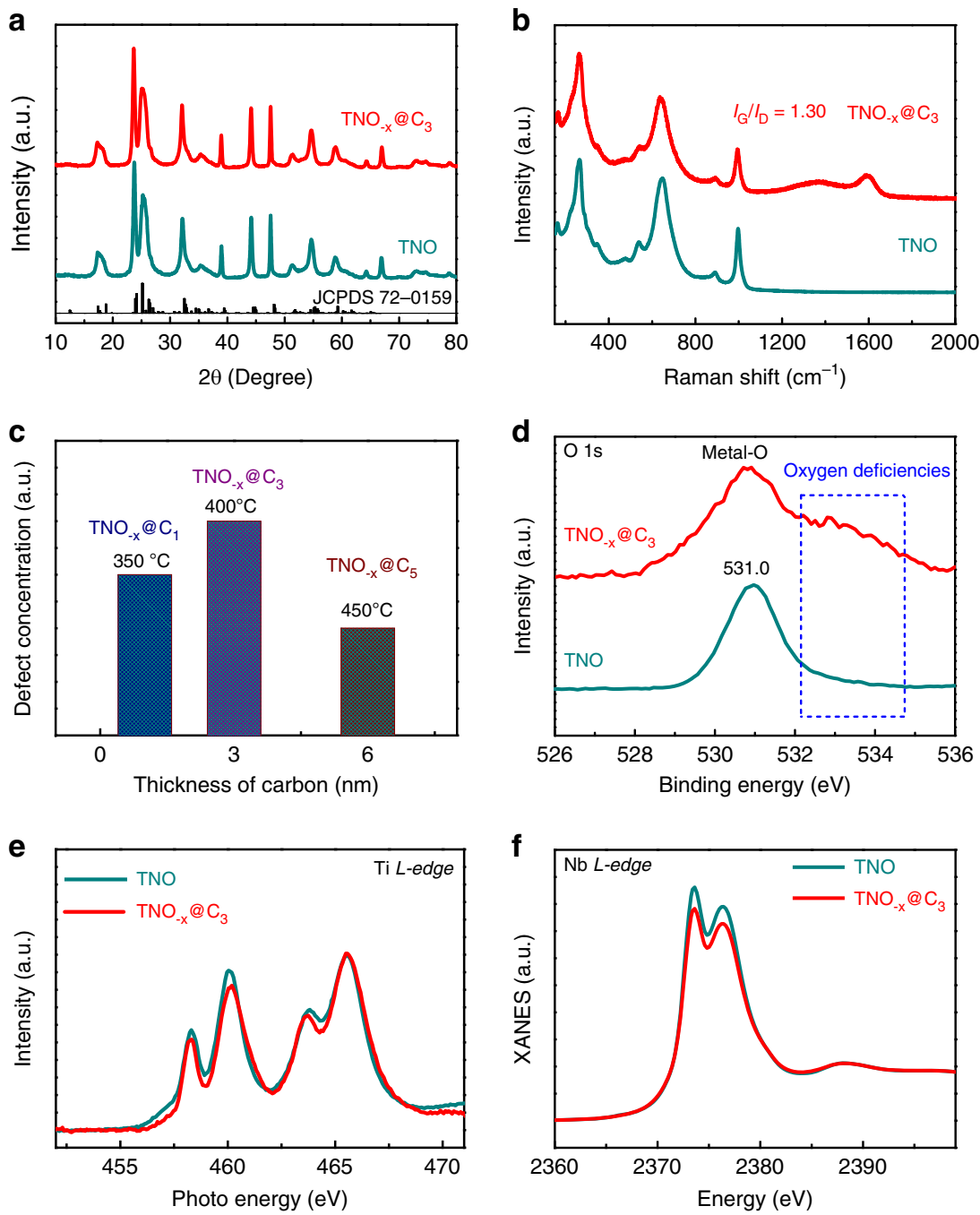

Fig. 2 Phase and composition characterization of TNO and TNO $\mathbf{r}_{-\mathbf{x}} @ \mathbf{C}_{\mathbf{3}}$. a XRD patterns. $\mathbf{b}$ Raman spectra. $\mathbf{c}$ The relationship of defect concentration and thickness of carbon. $\mathbf{d}$ XPS spectra of O $1 \mathrm{~s}$. e XANES spectra of Ti L-edge. $\mathbf{f}$ XANES spectra of Nb L-edge.

and $\mathrm{TNO}_{-x} @ \mathrm{C}_{5}$ composites are 2.3,3.2, and 6.8 wt.\%, respectively, implying the controllable carbon coating by acetylene decomposition.

To study the oxygen deficiencies of the samples, electron paramagnetic resonance (EPR) tests were carried out. The $\mathrm{TNO}_{-x} @ \mathrm{C}_{3}$ shows the strongest EPR signal at $g=2.0$ (typical signal of oxygen vacancies) (Supplementary Fig. 9d), higher than those of TNO $-x @ \mathrm{C}_{1}$ and $\mathrm{TNO}_{-x} @ \mathrm{C}_{5}$ counterparts, while the pure TNO nanosheet sample only displays a flat line without obvious oxygen vacancy ${ }^{23,24}$. These results clearly confirm the presence of abundant oxygen deficiencies in $\mathrm{TNO}_{-x} @ \mathrm{C}_{3}$. The TNO ${ }_{-x} @ \mathrm{C}_{3}$ was also chosen as a representative to study its physicochemical property based on the optimized carbon layer and oxygen deficiency (Fig. 2c). As observed from X-ray photoelectron spectra (XPS, Fig. 2d), the O $1 \mathrm{~s}$ spectra of pure TNO nanosheets only presents an individual peak at $531.0 \mathrm{eV}$, belonging to metal-O bonding $8,23,24$. However, apart from the metal-O bonding, the $\mathrm{TNO}_{-x} @ \mathrm{C}_{3}$ nanosheets also exhibit another peak characteristic of metal-OH bonding $(532.6 \mathrm{eV})$, further indicating the existence of oxygen deficiencies in $\mathrm{TNO}_{-x} @ \mathrm{C}_{3}^{8,23,24}$. Meanwhile, the valence state change of $\mathrm{Ti}$ and $\mathrm{Nb}$ caused by oxygen deficiency is also proven by the $\mathrm{Ti} 2 \mathrm{p}$ and $\mathrm{Nb} 3 \mathrm{~d}$ XPS spectra (Supplementary Fig. $9 \mathrm{e}-\mathrm{f})^{25-27}$. It is seen that, for the pure TNO nanosheets, two core levels of Ti $2 \mathrm{p}$ are assigned to $\mathrm{Ti} 2 \mathrm{p}_{1 / 2}(465.1 \mathrm{eV})$ and $\mathrm{Ti} 2 \mathrm{p}_{3 / 2}$ $(459.4 \mathrm{eV})$, respectively. While the Ti peaks of $\mathrm{TNO}_{-x} @ \mathrm{C}_{3}$ shift left as compared with the pure TNO nanosheets, demonstrating the existence of $\mathrm{Ti}^{3+}$ in the $\mathrm{TNO}_{-x} @ \mathrm{C}_{3}$ (Supplementary Fig. 9e). In the meantime, $\mathrm{Nb} 3 \mathrm{~d}$ spectra also show two characteristic core levels for the pure TNO nanosheets, indexed well into $\mathrm{Nb} 3 \mathrm{~d}_{5 / 2}(207.6 \mathrm{eV})$ and $\mathrm{Nb} 3 \mathrm{~d}_{3 / 2}(210.4 \mathrm{eV})$, respectively. While lower binding-energy

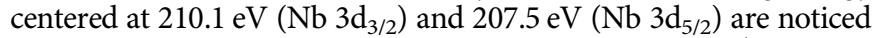
for the $\mathrm{TNO}_{-x} @ \mathrm{C}_{3}$ composite, demonstrating more $\mathrm{Nb}^{4+}$ ions in the $\mathrm{TNO}_{-x} @ \mathrm{C}_{3}$ sample (Supplementary Fig. 9f). In short, the presence of $\mathrm{Ti}^{3+}$ and $\mathrm{Nb}^{4+}$ further verifies the presence of oxygen deficiency induced by such a carbon engineering strategy.

In addition, X-ray absorption near-edge structure (XANES) analysis was employed to investigate the defective chemistry. Figure 2e shows the Ti $L$-edge XANES spectra, where four peaks centered at maxima over the energy range belong to $L 3_{\mathrm{t} 2 \mathrm{~g}}, L 3_{\mathrm{eg}}$, $L 2_{\mathrm{t} 2 \mathrm{~g}}$, and $L 2_{\mathrm{eg}}$, respectively. The lowered peak intensity of $t_{2 g}$ in $\mathrm{TNO}_{-x} @ \mathrm{C}_{3}$ indicates that the Ti in $\mathrm{TNO}_{-x} @ \mathrm{C}_{3}$ sample has a lower valence state due to partially occupied electronic states of $e_{g}$ and $t_{2 g}$ at the surface region. The above difference is attributed to the presence of oxygen deficiencies, which can cause loss of longrange order ${ }^{28}$. Meanwhile, Fig. $2 \mathrm{f}$ presents the normalized $\mathrm{Nb} L_{2}$ and $L_{3}$-edge XANES absorption spectra of the two samples, matching well with the transition of $2 p 1 / 2 \rightarrow$ nd and $2 p 3 / 2 \rightarrow$ nd, respectively. Notice that the $\mathrm{TNO}_{-x} @ \mathrm{C}_{3}$ shows lower peak intensity, suggesting a number decrease of $\mathrm{Nb} 3 \mathrm{~d}$ holes as a result of the generated oxygen deficiencies ${ }^{23,29}$. Moreover, as shown in 
a
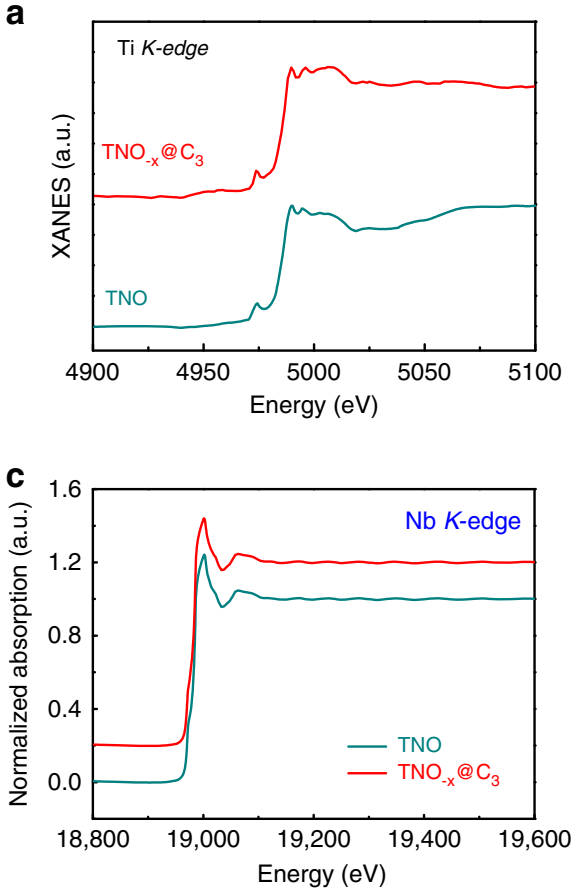

e

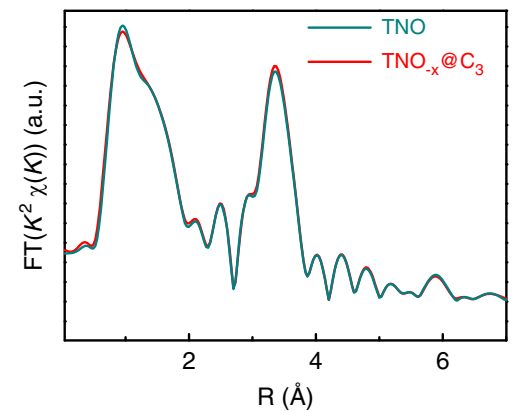

b
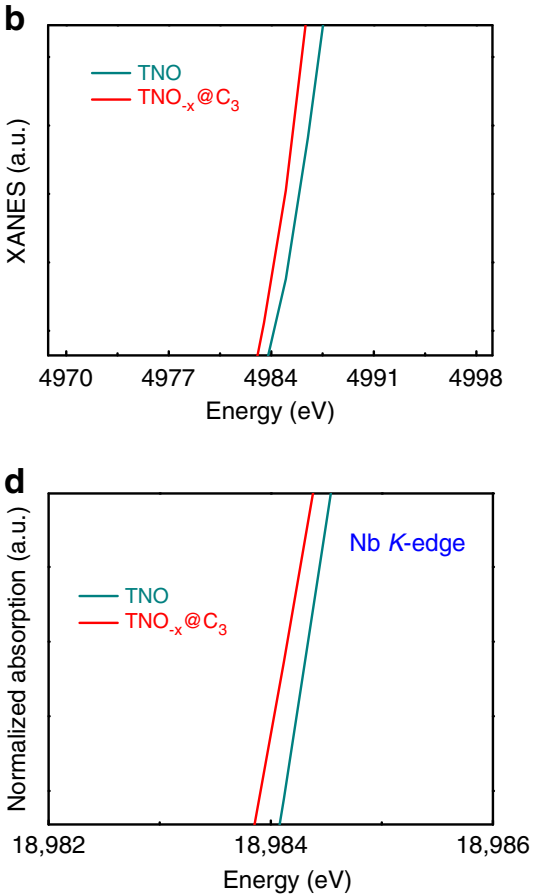

f

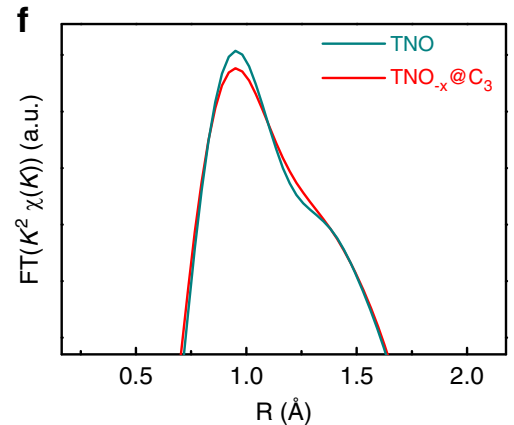

Fig. 3 XANES and XAFS spectra of pure TNO and TNO $\mathbf{- n}_{\mathbf{x}} @ \mathbf{C}_{\mathbf{3}}$ samples. a Ti $K$-edge spectra. b Enlarged Ti $K$-edge spectra. c Nb $K$-edge spectra. d Enlarged Nb $K$-edge spectra. e Fourier transform of the $k^{2}$-weighted Nb $K$-edge of the EXAFS spectra. $\mathbf{f}$ Fourier transform of the $k^{2}$-weighted Nb $K$-edge of the enlarged EXAFS spectra.

Fig. 3a, b, the Ti K-edge spectra of $\mathrm{TNO}_{-x} @ \mathrm{C}_{3}$ exhibits similar characteristic compared with the TNO phase. Nevertheless, the $\mathrm{TNO}_{-x} @ \mathrm{C}_{3}$ sample displays lower valance state according to left shift of absorption edge position, implying the presence of abundant oxygen deficiencies. In order to deepen the understanding of the electronic state and oxygen deficiencies, XAFS spectra of $\mathrm{Nb} K$-edge were tested for both of the samples. The XANES of the $\mathrm{TNO}_{-x} @ \mathrm{C}_{3}$ shows a smaller energy of the absorption edge (Fig. 3c, d), consistent with the XPS results. Figure $3 \mathrm{e}, \mathrm{f}$ exhibits the corresponding $R$ space curves of $k^{2}[\chi(k)]$ weighted Fourier transform spectra ${ }^{30,31}$. The peaks centered at $0-2 \AA$ in these TNO samples belong to $\mathrm{Nb}-\mathrm{O}$ bond, and another peak at $3-4 \AA$ is attributed to $\mathrm{Nb}-\mathrm{Nb}$ or $\mathrm{Nb}-\mathrm{Ti}$ vectors ${ }^{23,32}$. It is worth noting that the $\mathrm{TNO}_{-x} @ \mathrm{C}_{3}$ displays lower intensity in the $\mathrm{Nb}-\mathrm{O}$ bond, indicating the lower oxygen coordination number and more oxygen deficiencies. The above results support each other to demonstrate that such boundary carbon engineering could not only provide scalable carbon layer, but also introduce oxygen deficiencies in the TNO.

First-principle calculations of TNO. To illustrate the influence of oxygen vacancy on the properties of TNO, the first-principle calculations were employed. As shown in Supplementary Fig. 10, there are five main cases of oxygen vacancies: oxygen vacancy between $\mathrm{Ti}$ and $\mathrm{Nb}$ atoms $\left(\mathrm{TNO}_{-x}(\mathrm{O}: \mathrm{Ti}-\mathrm{Nb})\right)$, between $\mathrm{Nb}$ and $\mathrm{Nb}$ atoms $\left(\mathrm{TNO}_{-x}(\mathrm{O}: \mathrm{Nb}-\mathrm{Nb})\right)$, between $\mathrm{Nb}, \mathrm{Nb}$, and $\mathrm{Nb}$ atoms $\left(\mathrm{TNO}_{-x}(\mathrm{O}: \mathrm{Nb}-\mathrm{Nb}-\mathrm{Nb})\right)$, between $\mathrm{Nb}, \mathrm{Ti}$, and $\mathrm{Nb}$ atoms $\left(\mathrm{TNO}_{-x}(\mathrm{O}: \mathrm{Nb}-\mathrm{Ti}-\mathrm{Nb})\right)$, between $\mathrm{Ti}, \mathrm{Nb}$, and $\mathrm{Ti}$ atoms $\left(\mathrm{TNO}_{-x}\right.$ $(\mathrm{O}: \mathrm{Ti}-\mathrm{Nb}-\mathrm{Ti})$ ). Their crystal structures are optimized and the corresponding lattice parameters and energies are listed in Supplementary Table 1 . Note that the $\mathrm{TNO}_{-x}(\mathrm{O}: \mathrm{Nb}-\mathrm{Nb})$ has relatively low energies than the others, demonstrating that the $\mathrm{TNO}_{-x}(\mathrm{O}: \mathrm{Nb}-\mathrm{Nb})$ is more stable and the oxygen atom is prone to lose at the position. Moreover, the total density of states and partial density of states were calculated (Fig. 4a, b and Supplementary Fig. 11). For the valence band of the perfect TNO, it is found that the strong hybridizations between $\mathrm{Ni} 3 d-\mathrm{O} 2 p$ and $\mathrm{Ti} 3 d-\mathrm{O} 2 p$ are revealed by their obvious overlaps and consistent amplitudes $^{33}$. Impressively, the electron conductivity can also be significantly affected by oxygen vacancy. For the defective $\mathrm{TNO}_{-x}$ $(\mathrm{O}: \mathrm{Ti}-\mathrm{Nb})$ and $\mathrm{TNO}_{-x}(\mathrm{O}: \mathrm{Nb}-\mathrm{Nb})$, the Fermi level transforms from the top of the valence band of the perfect crystal to the bottom of the conduction band of defective $\mathrm{TNO}_{-x}$, which can greatly improve the intrinsic electronic conductivity of electrode material. For the defective $\mathrm{TNO}_{-x}(\mathrm{O}: \mathrm{Nb}-\mathrm{Nb}-\mathrm{Nb}), \mathrm{TNO}_{-x}(\mathrm{O}:$ $\mathrm{Nb}-\mathrm{Ti}-\mathrm{Nb})$, and $\mathrm{TNO}_{-x}(\mathrm{O}: \mathrm{Ti}-\mathrm{Nb}-\mathrm{Ti})$, not only the Fermi level 

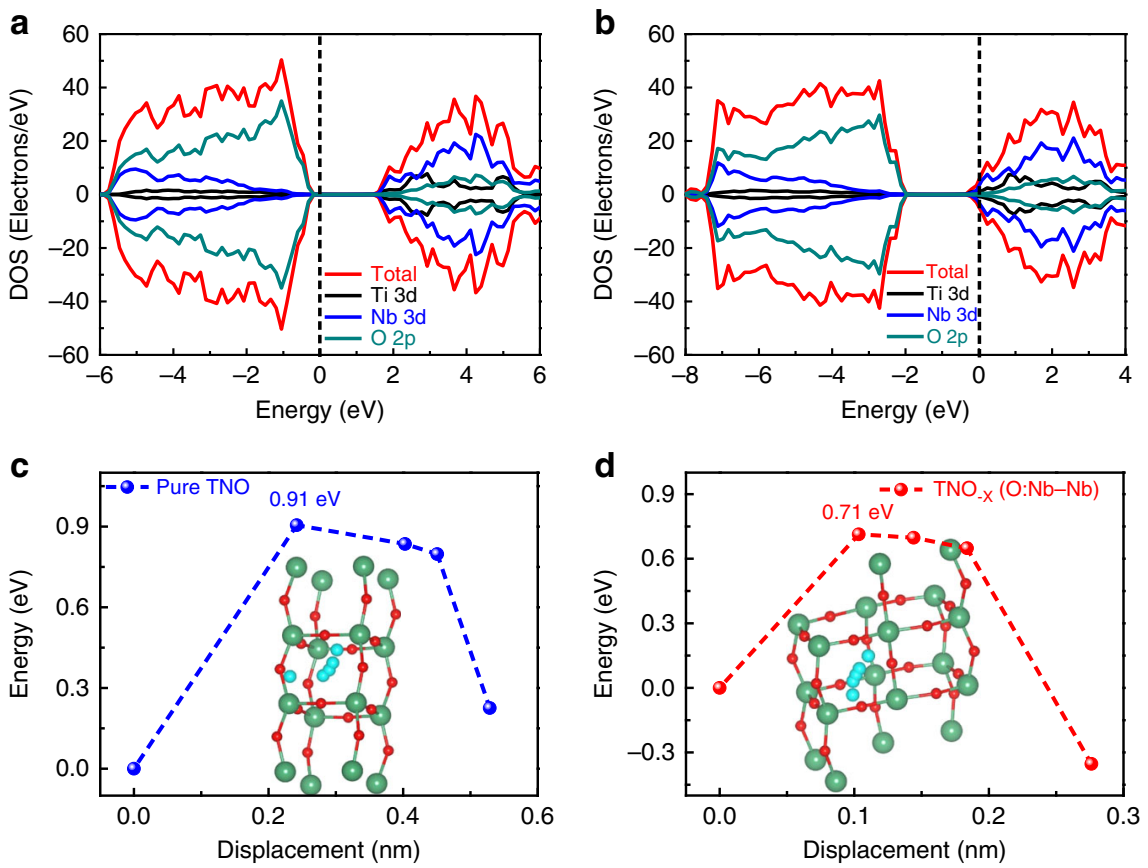

e
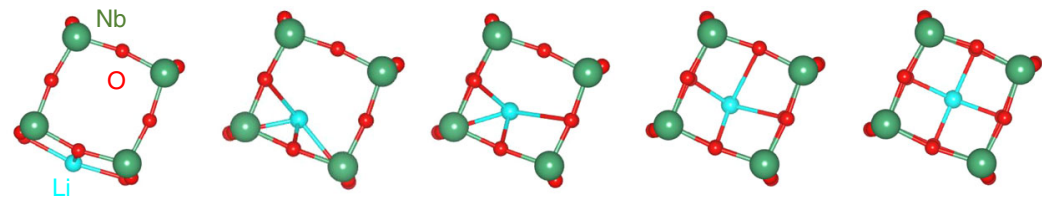

f
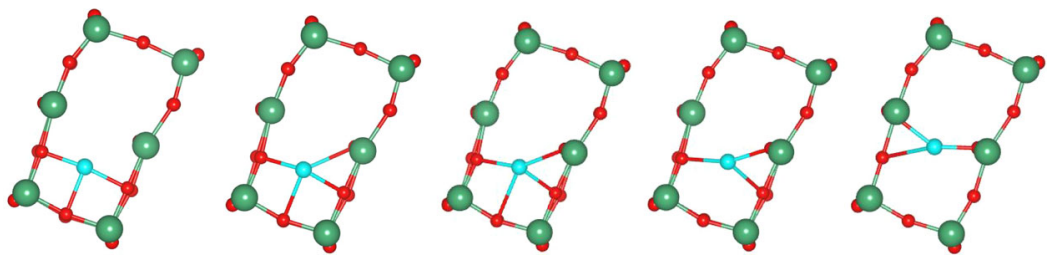

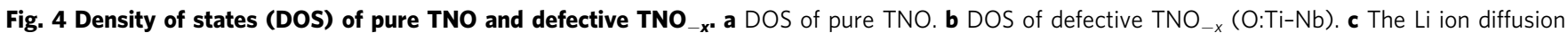
energy barrier for TNO. $\mathbf{d}$ The Li ion diffusion energy barrier for TNO $\mathrm{TN}_{-x}(\mathrm{O}: \mathrm{Nb}-\mathrm{Nb})$. e The Li ion diffusion pathways for TNO. $\mathbf{f}$ The Li ion diffusion pathways for $\mathrm{TNO}_{-x}(\mathrm{O}: \mathrm{Nb}-\mathrm{Nb})$.

moves toward high-energy direction, but also the impurity levels appear between the valence and conduction band. And the composition of the impurity level is heavily dependent on the oxygen vacancy position. Due to the existence of the impurity levels, the electronic conductivity of the defective $\mathrm{TNO}_{-x}$ can be greatly enhanced. In addition, it could be seen that the partial charge density of the perfect crystal has a strong locality near the Fermi plane, while the partial charge density of the crystal with oxygen vacancy is relatively dispersed. This further indicates that oxygen deficiency can improve electrical conductivity (Supplementary Fig. 12). Moreover, the Li ion diffusion pathways and energy barrier for $\mathrm{TNO}$ and $\mathrm{TNO}_{-x}(\mathrm{O}: \mathrm{Nb}-\mathrm{Nb})$ were further explored using nudged elastic-band (NEB) method. Herein, the defective $\mathrm{TNO}_{-x}(\mathrm{O}: \mathrm{Nb}-\mathrm{Nb})$ was chosen as a case due to lowest formation energy. For simplification, the smallest crystal structure unit was used in the NEB calculation process. As shown in Fig. 4e, $\mathrm{f}$, the $\mathrm{Li}$ ion diffusion pathways of TNO and $\mathrm{TNO}_{-x}(\mathrm{O}: \mathrm{Nb}-\mathrm{Nb})$ are described, respectively. The initial site of $\mathrm{Li}$ ion is the lowest energy oxygen deficiency site and the final is the lowest energy interstitial site. Their corresponding energy barriers are shown in Fig. $4 \mathrm{c}$, d. It could be seen that the energy barrier of the pure TNO is only $0.91 \mathrm{eV}$, while the energy barrier of the $\mathrm{TNO}_{-x}(\mathrm{O}$ : $\mathrm{Nb}-\mathrm{Nb}$ ) reduces to $0.71 \mathrm{eV}$. This indicates that the $\mathrm{Li}$ ion is easier to migrate in defective $\mathrm{TNO}_{-x}(\mathrm{O}: \mathrm{Nb}-\mathrm{Nb})$ than the pure TNO. Based on the above results, enhanced electrical conductivity and ionic transfer are ensured for the $\mathrm{TNO}_{-x} @ \mathrm{C}_{3}$ composites and better Li ion storage performance can be anticipated.

Electrochemical performance of $\mathrm{TNO}_{-x} @ \mathrm{C}_{3}$ composites. The electrochemical performance was firstly monitored by charge-discharge tests in the voltage window of $1.0-2.5 \mathrm{~V}$ (Fig. 5a). The discharge specific capacity of $\mathrm{TNO}_{-x} @ \mathrm{C}_{3}$ is 280 $\mathrm{mA} \mathrm{h} \mathrm{g}^{-1}$, higher than that of pure TNO electrode $(217 \mathrm{mAhg}$ $-1)$. The improved electrochemical performance was also verified by electrochemical impedance spectrum (EIS) test. The $\mathrm{TNO}_{-x} @ \mathrm{C}_{3}$ electrode presents smaller charge-transfer resistance and ohmic resistance (Fig. 5b), indicating that the oxygen deficiencies and carbon layer can facilitate charge transfer and boost reaction kinetics. Apparently, the $\mathrm{TNO}_{-x} @ \mathrm{C}_{3}$ electrode exhibits superior high-rate performance with large capacities of $253 \mathrm{~mA} \mathrm{~h}$ $\mathrm{g}^{-1}, 226 \mathrm{~mA} \mathrm{~h} \mathrm{~g}^{-1}$, and $197 \mathrm{~mA} \mathrm{hg}^{-1}$ at $5 \mathrm{C}, 10 \mathrm{C}$, and $20 \mathrm{C}$ (Fig. 5c), respectively, superior to those of the TNO electrode $\left(195 \mathrm{~mA} \mathrm{~h} \mathrm{~g}^{-1}\right.$ at $5 \mathrm{C}, 162 \mathrm{~mA} \mathrm{~h} \mathrm{~g}^{-1}$ at $10 \mathrm{C}$, and $136 \mathrm{~mA} \mathrm{~h} \mathrm{~g}^{-1}$ at $20 \mathrm{C}$ ) (Supplementary Fig. 13c). Note that the introduction of abundant oxygen deficiencies and high-quality carbon coating can enhance electrochemical rate performance because of greatly 

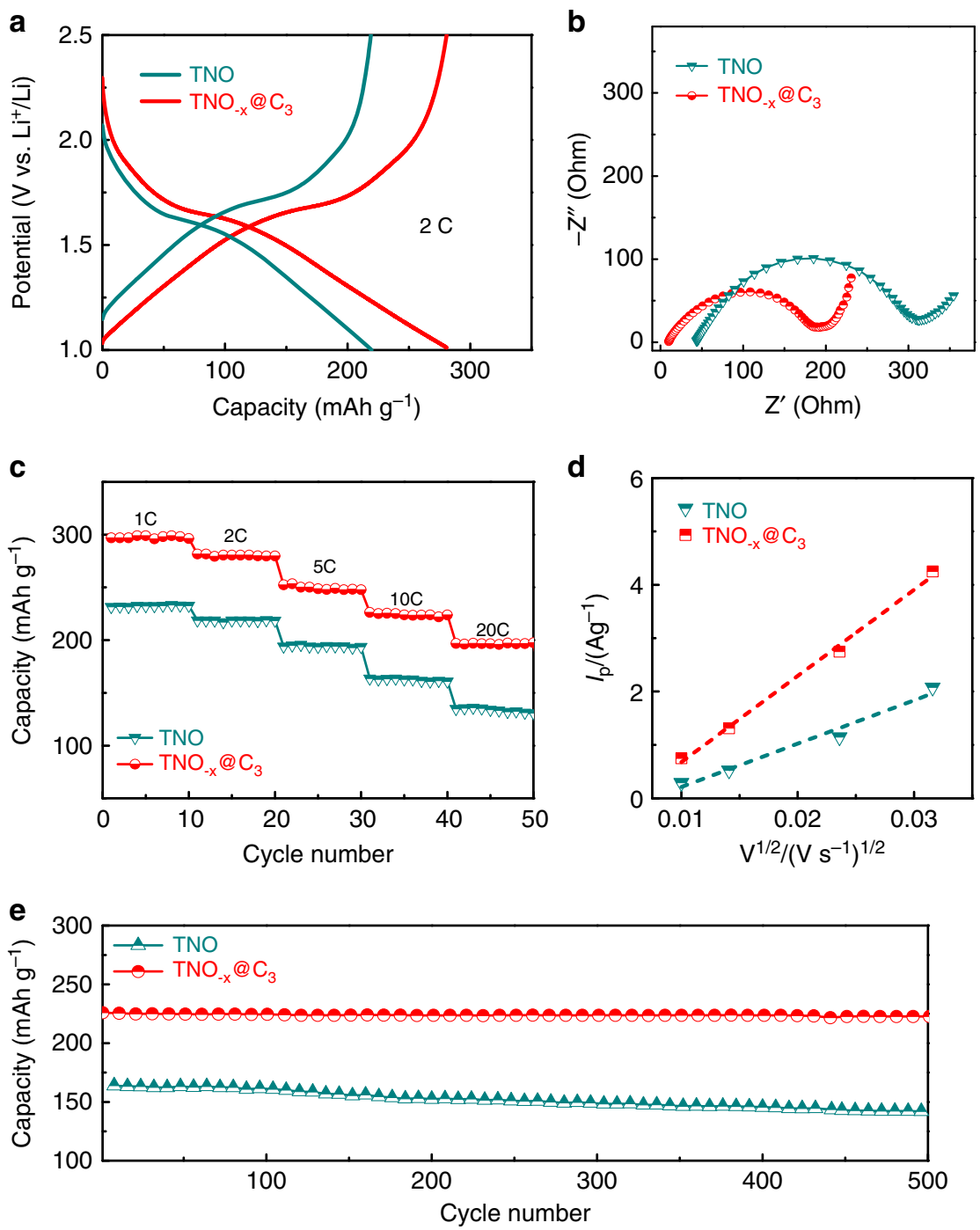

Fig. 5 Electrochemical characterization of TNO and TNO ${ }_{-\mathbf{x}} @ \mathbf{C}_{\mathbf{3}}$ electrodes. a Discharge/charge profiles. b Nyquist plots at the fully discharge state at the first cycle. c Rate capability. d Peak current $I_{p}$ as a function of square root of scan rate $V^{1 / 2}$. e Cycling stability at $10 \mathrm{C}$.

improved intrinsic conductivity and integrated conductive network. Meanwhile, the obtained $I_{\mathrm{p}}$ (intensity of $\mathrm{Nb}^{4+} / \mathrm{Nb}^{5+}$ anodic peak) is plotted as a function with $\mathrm{V}^{1 / 2}(\mathrm{~V}$ is the scan rates) in Fig. 5d and Supplementary Fig. 13a-b, whose slope stands for the $\mathrm{Li}^{+}$diffusion coefficient. Obviously, the $\mathrm{TNO}_{-x} @ \mathrm{C}_{3}$ electrode displays a steep slope with 1.98 times larger than that of the pure TNO electrode, suggesting larger $\mathrm{Li}^{+}$diffusion coefficient. More importantly, long-term durability is achieved for the $\mathrm{TNO}_{-x} @ \mathrm{C}_{3}$ electrode (Fig. 5e), which displays a discharge capacity of $223 \mathrm{mAhg}^{-1}$ at $10 \mathrm{C}$ with a capacity retention of $98.7 \%$ over 500 cycles. In contrast, the TNO counterpart only shows a capacity of $140 \mathrm{~mA} \mathrm{~h} \mathrm{~g}^{-1}$ (capacity retention of $85.9 \%$ over 500 cycles). The enhanced rate performance and long cycle life of $\mathrm{TNO}_{-} @ \mathrm{C}_{3}$ electrode arise from the synergistic effects between the oxygen deficiencies existence and controllable boundary carbon coating.

\section{Discussion}

In addition, a deeper understanding of superior lithium storage performance by synergistic engineering of carbon and deficiency was investigated through ex situ HEXRD to detect the lattice parameters of the pure and $\mathrm{TNO}_{-x} @ \mathrm{C}_{3}$ (Fig. 6a, b). The nanoscale nature of both materials gives rise to a significant line broadening of the diffraction peaks, therefore Lebail method with size model of spherical harmonics was adopted for the refinements of the XRD patterns. All the Bragg peaks could be successfully described with the monoclinic $\mathrm{ReO}_{3}$ shear structure (space group, $\mathrm{C} 2 / \mathrm{m}$ ), indicating that the carbon will not change the long-range coherence of TNO framework ${ }^{4}$. Nevertheless, a remarkable lattice expansion is revealed for the $\mathrm{TNO}_{-x} @ \mathrm{C}_{3}$ sample in contrast with the pure TNO (Supplementary Table 2). This could be ascribed to the existence of $\mathrm{Ti}^{3+}$ and $\mathrm{Nb}^{4+}$ (with larger ion-radiuses than $\mathrm{Ti}^{4+}$ and $\mathrm{Nb}^{5+}$ ) that are reduced by the oxygen vacancies ${ }^{7,34}$. The increased lattice parameters of $\mathrm{TNO}_{-x} @ \mathrm{C}_{3}$ might further indicate the probable missing location of lattice oxygen is in the $\mathrm{Nb}-\mathrm{Nb}$ site $\left(\mathrm{TNO}_{-x}(\mathrm{O}: \mathrm{Nb}-\mathrm{Nb})\right)$ according to the consistent results of HEXRD and Density functional theory (DFT) calculations. The lattice expansion further suggests that the $\mathrm{TNO}_{-x} @ \mathrm{C}_{3}$ electrode is beneficial for $\mathrm{Li}$ ions transfer. In the meantime, in situ synchrotron HEXRD measurements were also performed on both pure TNO and $\mathrm{TNO}_{-x} @ \mathrm{C}_{3}$ within the first discharge-charge cycle. From the 2D contour plots of the XRD patterns (Fig. 6c, d), remarkably, a striking shift of all the Bragg peaks is observed for the pure TNO, while the peak shifting for the $\mathrm{TNO}_{-x} @ \mathrm{C}_{3}$ is less obvious. In addition, the pure TNO patterns also show a more anisotropic feature in contrast with $\mathrm{TNO}_{-x} @ \mathrm{C}_{3}$. Two typical groups of the 

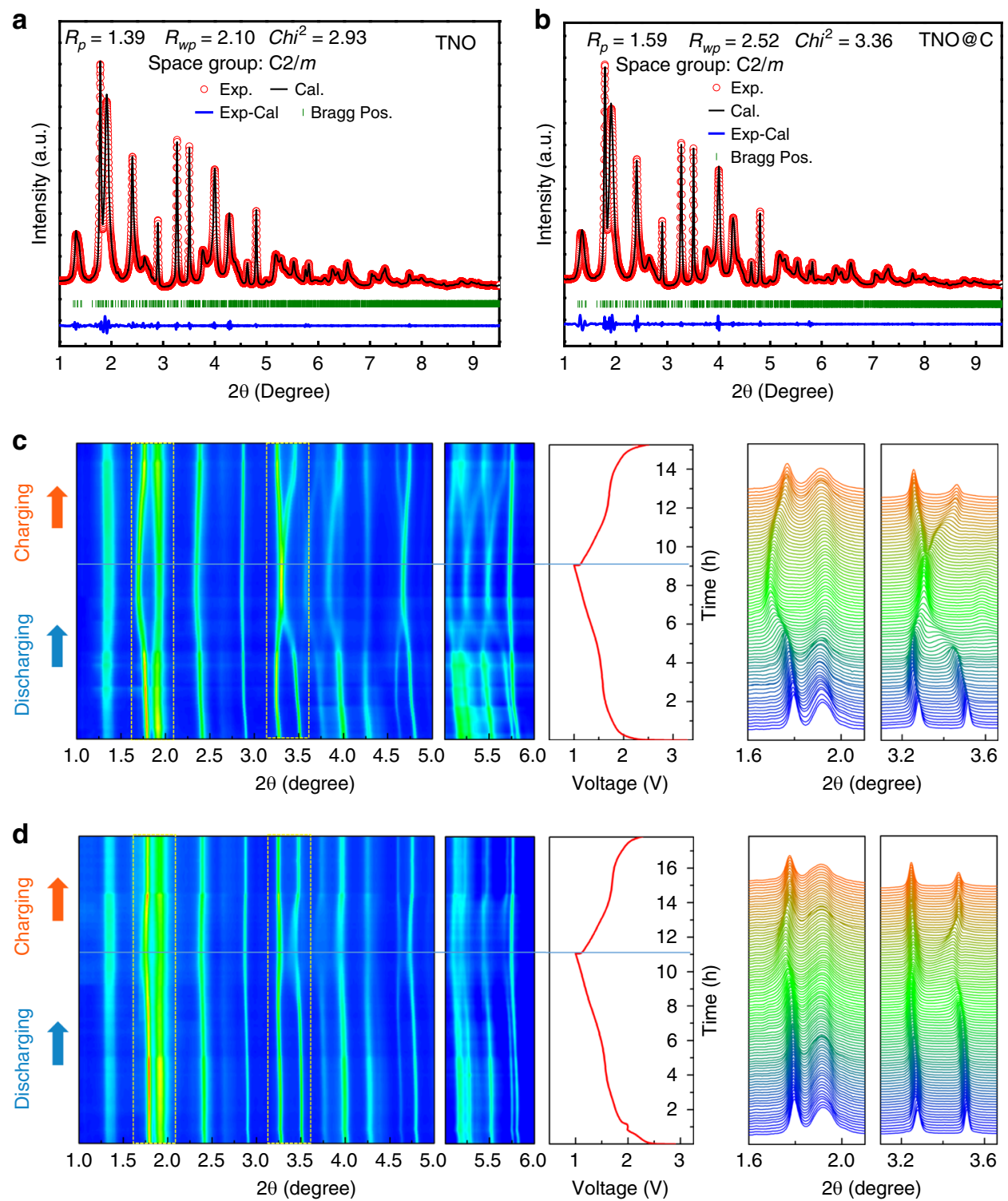

Fig. 6 Synchrotron HRXRD characterization of TNO and TNO $-\mathbf{x} @ \mathbf{C}_{\mathbf{3}}$ a Ex situ synchrotron HRXRD characterization of TNO. b Ex situ synchrotron HRXRD characterization of $\mathrm{TNO}_{-x} @ \mathrm{C}_{3} . \mathbf{c}$ In situ synchrotron HEXRD characterization voltage profile and corresponding contour plot of the XRD pattern evolution of TNO during the first charge-discharge process. $\mathbf{d}$ In situ synchrotron HEXRD characterization voltage profile and corresponding contour plot of the XRD pattern evolution of $\mathrm{TNO}_{-x} @ \mathrm{C}_{3}$ during the first charge-discharge process. (Contour plot of the (011), (400), (317), and (700) peaks evolution).

peak profiles are presented to detail these behaviors. Accordingly, it could be speculated that the lattice of the $\mathrm{TNO}_{-} @ \mathrm{C}_{3}$ experiences a moderate structural change over cycling due to modulation of synergistic engineering of carbon and deficiency. The lattice evolutions of both materials are extracted from the in situ XRD patterns for a more specific view. For the pure TNO, four structural transitions occur continuously as the lithium ions embed into the framework, leading to five monoclinic structures (referred as M1-M5) over the whole discharging stage (Fig. 7a). These transitions are fingerprinted by the abruptly evolutive breaks of the axes, as it signals the potential barriers to be overcome $^{35,36}$. In detail, the transitions from M1 to M4 (3.0-1.5 V) are irreversible, during which the lattice parameters exhibit a nonmonotonic dependence on lithium content. This period could be recognized as the activation process, i.e., the rearrangements of host-atoms to tolerate Li-insertion, which could inevitably induce mechanical fractures that deteriorate reversible capacity and cyclic kinetics. As for the $\mathrm{TNO}_{-x} @ \mathrm{C}_{3}$, only one structural transition between two monoclinic structures ( $\mathrm{Cc} 1$ and $\mathrm{Mc} 2$ ) is observed upon discharging, and just as importantly, the lattice anisotropy is also significantly weakened (Fig. 7b) compared with the pure TNO material. This provides evidence that the harmful activation of TNO could be efficiently inhibited through building these carbon-coated boundaries. In addition, the subsequent delithiation leads to a coupled expansion of $a$-/c-axis and an independent contraction of $b$-axis for both materials, indicating that the $\mathrm{Li}^{+}$diffusion path could be along $b$-direction. Notably, an obvious weakening of the lattice changes along all directions is observed for the $\mathrm{TNO}_{-x} @ \mathrm{C}_{3}$. For these two materials, this solidsolution reaction is almost reversible, so the weakening of the periodic structural fluctuation in the $\mathrm{TNO}_{-x} @ \mathrm{C}_{3}$ could reduce the repeated lattice strain and eventually lead to a significant improvement on the cycling performance. To better understand the structural features of $\mathrm{TNO}_{-x} @ \mathrm{C}_{3}$ electrodes, ex situ electrochemical dilatometry was employed. Supplementary Fig. 14 presents the electrode thickness variation of $\mathrm{TNO}_{-x} @ \mathrm{C}_{3}$ and $\mathrm{TNO}$ during the first galvanostatic discharge/charge cycle according to the SEM results (Supplementary Fig. 15). Obviously, discharge 

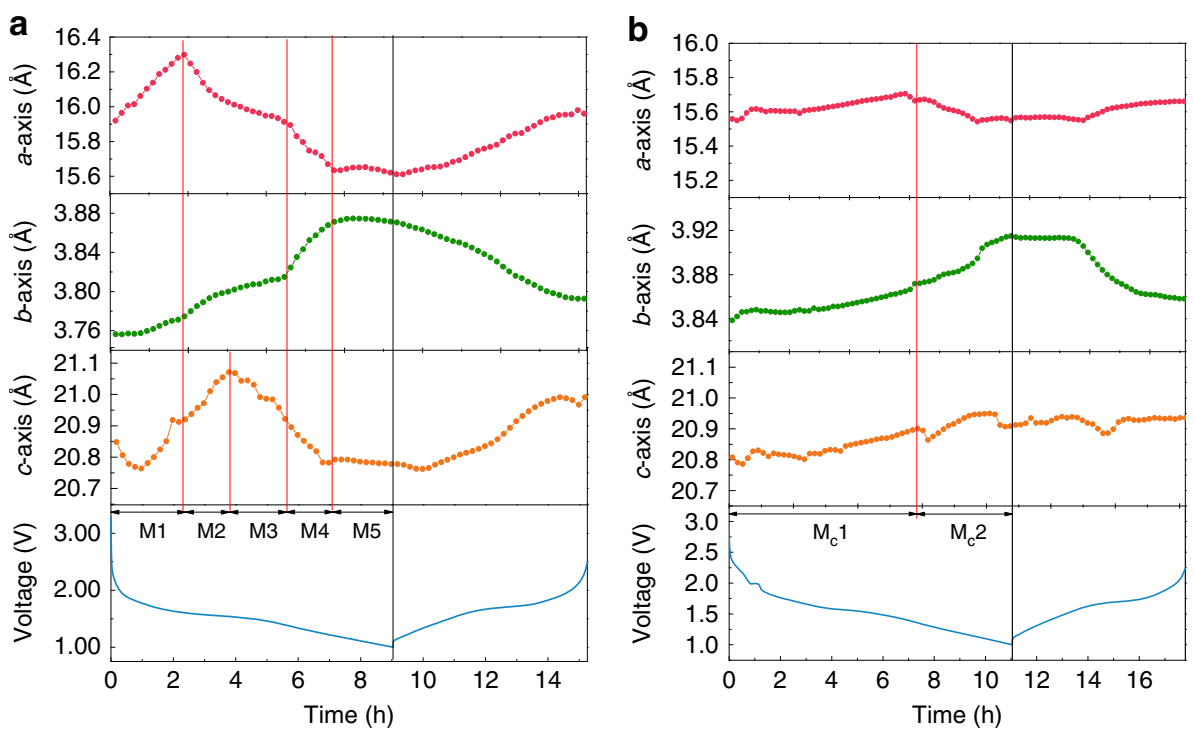

Fig. 7 The voltage profile and the lattice parameter evolution process. a pure TNO. b TNO $@ @ C_{3}$.

and charge processes are accompanied with a thickness increase and then decrease for two electrodes, respectively. In agreement with the results of in situ XRD analysis above, the $\mathrm{TNO}_{-x} @ \mathrm{C}_{3}$ electrode shows a lower expansion rate than TNO electrode, mainly due to the buffer function of boundary carbon coating. In all, from the structural point of view, the origin of the enhanced cycling performance of $\mathrm{TNO}_{-x} @ \mathrm{C}_{3}$ is twofold: the inhibition of the activation process and the weakening of the cyclic structural change. This could be explained by the stability of the carboncoated boundaries, which constrains the internal grains from complex phase transitions upon the initial lithiation and severe lattice change induced from the solid-solution reaction.

To summarize, we have verified a universal and controllable low-temperature engineering of carbon and deficiency down to primary-grain level to achieve fast charging/discharging electrode materials with conformal and thickness-adjustable boundary carbon. Impressively, relying on such exquisite boundary architecture, significantly improved electron transport and enlarged $\mathrm{Li}^{+}$diffusion path, shortened activation process and better structural stability are readily realized in the electrode materials due to the regulation of oxygen vacancy and weakened lattice dynamical anisotropy. As a result, the enhanced high-rate energy storage performance has been triggered in the $\mathrm{TNO}_{-x} @ \mathrm{C}_{3}$ electrodes, which show superior rate capability $\left(197 \mathrm{~mA} \mathrm{~h} \mathrm{~g}^{-1}\right.$ at $20 \mathrm{C}$, corresponding to $3 \mathrm{~min}$ charge time) and remarkable cycling durability in lithium ion storage, much better than other counterparts (Supplementary Table 3). Most importantly, our developed engineering of carbon and deficiency is versatile and demonstrated to be applicable in a series of metal oxides systems ( $\mathrm{TNO}_{-x} @ \mathrm{C}, \mathrm{Nb}_{2} \mathrm{O}_{5-x} @ \mathrm{C}, \mathrm{TiO}_{2-x} @ \mathrm{C}$, and $\mathrm{ZnO}_{-x} @ \mathrm{C}$ ) with adjustable structure, morphology, and composition. Our work reveals a ground-breaking method in the boundary carbon design/decoration of composite materials for electrochemical energy storage.

\section{Methods}

Synthesis of TNO ${ }_{-} @ \mathbf{C}_{\mathbf{3}}$ composites. First, the 3D hierarchical porous pure TNO were fabricated via a facile solvothermal method. The puffed rice was annealed at $800^{\circ} \mathrm{C}$ for $3 \mathrm{~h}$ in Ar to obtain PRC as the sacrificial carbon template. Then, $0.56 \mathrm{~g}$ Ti- $\left(\mathrm{OC}_{3} \mathrm{H}_{7}\right)_{4}$ and $2.7 \mathrm{~g} \mathrm{NbCl}_{5}$ were added into $60 \mathrm{~mL}$ ethanol to form the homogeneous solution after stirring. Then, the above solution was transferred into a Teflon-linked steel autoclave with the PRC immersed into it, and kept at $200{ }^{\circ} \mathrm{C}$ for $10 \mathrm{~h}$. After that, the as-obtained materials were annealed in air at $800^{\circ} \mathrm{C}$ for $2 \mathrm{~h}$ to form pure 3D hierarchical porous TNO. Finally, the 3D hierarchical porous
TNO powder was annealed at $400{ }^{\circ} \mathrm{C}$ for $1 \mathrm{~h}$ in $\mathrm{C}_{2} \mathrm{H}_{2}$ atmosphere to obtain $\mathrm{TNO}_{-x} @ \mathrm{C}_{3}$ composites. For comparison, the TNO $\mathrm{TN}_{-x} @ \mathrm{C}_{1}$ and $\mathrm{TNO}_{-x} @ \mathrm{C}_{5}$ composites were obtained by annealing at $350^{\circ} \mathrm{C}$ and $450{ }^{\circ} \mathrm{C}$ for $1 \mathrm{~h}$ in $\mathrm{C}_{2} \mathrm{H}_{2}$ atmosphere, respectively.

Samples characterizations. The morphologies and microstructures of all samples were monitored by SEM (Hitachi S-4800) and TEM-HRTEM (JEOL 2100F at $200 \mathrm{kV}$ ) and spherical aberration-corrected scanning transmission electron microscopy (JEOL 2100F). XRD (Rigaku D/MAX 2550/PC) patterns were recorded in the range of $10-80^{\circ}$. Raman spectra were measured under laser excitation at $514 \mathrm{~nm}$ (LabRam HR UV). TG measurement was carried out by using Netzsch STA 449C thermal analyser. The chemical components and valence state were conducted by XPS (eSCALAB250Xi). XANES spectra (Ti $K$-edge and Nb $L$-edge) were collected at the 4W7A beamline station in Beijing Synchrotron Radiation Facility (BSRF, operated at $2.5 \mathrm{GeV}$ with a maximum current of $250 \mathrm{~mA}$ ) of China. The spectra were performed in the total electron yield (TEY) mode and the sample drain current was collected with a base pressure under than $5 \times 10^{-8} \mathrm{~Pa}$. X-ray absorption fine structure (XAFS) spectra ( $\mathrm{Nb} K$-edge) were carried out at the BL14W1 beamline station in Shanghai Synchrotron Radiation Facility (SSRF, operated at $3.5 \mathrm{GeV}$ with a maximum current of $230 \mathrm{~mA}$ ), China. The synchrotron beamline was monochromatized with $\mathrm{Si}$ (111) and $\mathrm{Si}$ (311) double-crystal monochromators to reduce the harmonic component. The data were collected at room temperature in fluorescence mode and analyzed according to the standard procedures using the Demeter software packages (University of Chicago). XANES spectra (Ti $L$-edge) were measured at beamline station BL12B in National Synchrotron Radiation Laboratory (NSRL, operated at $800 \mathrm{MeV}$ with a maximum current of $300 \mathrm{~mA}$ ) of China. The samples were placed on double-sided carbon tape for X-ray spectroscopy and all spectra were obtained with the TEY mode ${ }^{37}$. The "a.u." was the abbreviation for "arbitrary units".

Measurements of electrochemical performance. For the electrochemical performance evaluation, the working electrode was prepared by mixing TNO or $\mathrm{TNO}_{-x} @ \mathrm{C}_{3}$, Super $\mathrm{P}$ conductive carbon, and polyvinylidene fluoride in an 80:10:10 weight ratio, the lithium foil and microporous polypropylene film (Celgard, 2300) were used as counter electrode and separator, respectively. The electrochemical properties were tested in CR2025-type coin cells using 1.0 $\mathrm{M} \mathrm{LiPF}_{6}$ in acetylene carbonate/dimethyl carbonate (EC/DEC, 1:1, by volume) as the electrolyte. EIS and cyclic voltammetry (CV) curves were conducted on a $\mathrm{CHI} 660 \mathrm{E}$ electrochemical workstation (CH Instruments Inc., Shanghai). CV tests were carried out from 1.0 to $2.5 \mathrm{~V}$ at different scan rates. For EIS, the amplitude of the sine perturbation signal was $5 \mathrm{mV}$, and the frequency was scanned from the highest $(100 \mathrm{kHz})$ to the lowest $(10 \mathrm{mHz})$. The galvanostatic charge/discharge measurement was performed on a NEWARE battery testing system between cutoff voltages of $1.0-2.5 \mathrm{~V}\left(\mathrm{vs} . \mathrm{Li} / \mathrm{Li}^{+}\right)$ at different current densities at room temperature. The loading amount of active material was about $2 \mathrm{mg} \mathrm{cm}^{-2}\left(1 \mathrm{C}=396 \mathrm{~mA} \mathrm{~g}^{-1}\right)$.

Collection and analysis of in situ synchrotron XRD. The in situ XRD measurements were performed using 11-ID-C beamline at Advanced Photon Source (APS) of Argonne National Laboratory, with the X-ray wavelength of $0.1173 \AA$. Si (113) single crystal was used as monochromator for an X-ray beam at $105.7 \mathrm{keV}$. In a typical in situ collection, the coin cell with $\mathrm{TNO}$ or $\mathrm{TNO}_{-x}$ anode was operated 
with a constant current of $0.075 \mathrm{C}$. A single XRD pattern was obtained using a time period of $120 \mathrm{~s}^{35}$. The 2D diffraction patterns were collected in the transmission geometry with a Perkin-Elmer detector. The sample-to-detector distance, detector tilt angles and the instrumental resolution function were calibrated with a standard sample of $\mathrm{CeO}_{2}$. The integration and calibration of the 2D patterns were performed with the Fit2D software, and the lattice parameters were extracted from the integrated XRD patterns using Fullprof software. For the Lebail method, the backgrounds were subtracted by linear interpolation and the peak shapes were described using Thompson-Cox-Hastings profile function to separate the Gaussian and Lorentzian contributions to the Bragg peaks ${ }^{34,38}$. An anisotropic Lorentzian size broadening (spherical harmonics) was employed to describe the microstructure of the nanoscale TNO materials.

Calculations. DFT calculations were carried out to investigate the electronic structure by using the first-principle and projector-augmented wave ${ }^{39}$ as implemented in Vienna ab initio simulation package ${ }^{40}$. The spin-polarized generalized gradient approximation in the form of Perdew-Burke-Ernzerhof formulation ${ }^{41}$ was employed for the correlation functional and electronic exchange. The plane-wave energy cutoff was set to $500 \mathrm{eV}$. The convergence tolerances and

Hellmann-Feynman force on each atom were $0.01 \mathrm{eV}^{-1}$ and $10^{-5} \mathrm{eV}$ for maximum, respectively. Brillouin-zone integration was modeled by a periodic scheme $3 \times 3 \times 3 k$-point mesh, where the lattice vectors together with unit cell shape and size and atomic coordinates were relaxed ${ }^{33}$. The Li ion diffusion pathways calculations were employed using the climbing image nudged elastic-band method.

\section{Data availability}

The data that support the findings of this study are available from the authors upon reasonable request, see author contributions for specific datasets.

Received: 20 June 2019; Accepted: 6 December 2019;

Published online: 09 January 2020

\section{References}

1. Kim, N., Chae, S., Ma, J., Ko, M. \& Cho, J. Fast-charging high-energy lithiumion batteries via implantation of amorphous silicon nanolayer in edge-plane activated graphite anodes. Nat. Commun. 8, 812 (2017).

2. Luo, J. Y., Cui, W. J., He, P. \& Xia, Y. Y. Raising the cycling stability of aqueous lithium-ion batteries by eliminating oxygen in the electrolyte. Nat. Chem. 2, 760-765 (2010).

3. Cheng, Q. S. et al. Bulk $\mathrm{Ti}_{2} \mathrm{Nb}_{10} \mathrm{O}_{29}$ as long-life and high-power Li-ion battery anodes. J. Mater. Chem. A 2, 17258-17262 (2014).

4. Griffith, K. J., Wiaderek, K. M., Cibin, G., Marbella, L. E. \& Grey, C. P. Niobium tungsten oxides for high-rate lithium-ion energy storage. Nature 559, 556-563 (2018).

5. Lu, J., Wu, T. P. \& Amine, K. State-of-the-art characterization techniques for advanced lithium-ion batteries. Nat. Energy 2, 17011 (2017).

6. Hammami, A., Raymond, N. \& Armand, M. Lithium-ion batteries: runaway risk of forming toxic compounds. Nature 424, 635-636 (2003).

7. Cheng, X. B., Zhang, R., Zhao, C. Z. \& Zhang, Q. Toward safe lithium metal anode in rechargeable batteries: a review. Chem. Rev. 117, 10403-10473 (2017).

8. Deng, S. J. et al. Vertical graphene/ $\mathrm{Ti}_{2} \mathrm{Nb}_{10} \mathrm{O}_{29} /$ hydrogen molybdenum bronze composite arrays for enhanced lithium ion storage. Energy Storage Mater. 12, 137-144 (2018).

9. $\mathrm{Li}, \mathrm{H}$. S. et al. $\mathrm{TiNb}_{2} \mathrm{O}_{7}$ nanoparticles assembled into hierarchical microspheres as high-rate capability and long-cycle-life anode materials for lithium ion batteries. Nanoscale 7, 619-624 (2015).

10. Saravanan, K., Balaya, P., Reddy, M. V., Chowdari, B. V. R. \& Vittal, J. J. Morphology controlled synthesis of $\mathrm{LiFePO}_{4} / \mathrm{C}$ nanoplates for $\mathrm{Li}$-ion batteries. Energy Environ. Sci. 3, 457-463 (2010).

11. Jiang, J. et al. Putting Nanoarmors on Yolk-Shell Si@C Nanoparticles: a reliable engineering way to build better Si-based anodes for Li-ion batteries. ACS Appl. Mater. Interfaces 10, 24157-24163 (2018).

12. Wan, G. P. et al. $\mathrm{Ti}_{2} \mathrm{Nb}_{10} \mathrm{O}_{29}$ microspheres coated with ultrathin $\mathrm{N}$-doped carbon layers by atomic layer deposition for enhanced lithium storage. Chem. Commun. 55, 517-520 (2019).

13. Zhao, Y. et al. Robust metallic lithium anode protection by the molecularlayer-deposition technique. Small Methods 2, 1700417 (2018).

14. Xie, D. et al. Exploring advanced sandwiched arrays by vertical graphene and $\mathrm{N}$-doped carbon for enhanced sodium storage. Adv. Energy Mater. 7, 1601804 (2016).

15. Shen, $\mathrm{S}$. H. et al. A synergistic vertical graphene skeleton and $\mathrm{S}-\mathrm{C}$ shell to construct high-performance $\mathrm{TiNb}_{2} \mathrm{O}_{7}$-based core/shell arrays. J. Mater. Chem. A 6, 20195-20204 (2018)
16. Wang, J. J. et al. Size-dependent surface phase change of lithium iron phosphate during carbon coating. Nat. Commun. 5, 3415 (2014).

17. Liu, Y. L. et al. Formation of size-dependent and conductive phase on lithium iron phosphate during carbon coating. Nat. Commun. 9, 929 (2018).

18. Zhong, Y. et al. Popcorn inspired porous macrocellular carbon: rapid puffing fabrication from rice and its applications in lithium-sulfur batteries. Adv. Energy Mater. 8, 1701110 (2017).

19. $\mathrm{Lu}, \mathrm{X}$. et al. Atomic-scale investigation on lithium storage mechanism in $\mathrm{TiNb}_{2} \mathrm{O}_{7}$. Energy Environ. Sci. 4, 2638-2644 (2011).

20. Deng, S. J. et al. Phase modulation of $(1 \mathrm{~T}-2 \mathrm{H})-\mathrm{MoSe}_{2} / \mathrm{TiC}-\mathrm{C}$ shell/core arrays via nitrogen doping for highly efficient hydrogen evolution reaction. Adv. Mater. 30, 1802223 (2018).

21. Zhu, H. et al. Charge transfer drives anomalous phase transition in ceria. Nat. Commun. 9, 5063 (2018).

22. Liu, G. Y. et al. Synthesis of $\mathrm{Ti}_{2} \mathrm{Nb}_{10} \mathrm{O}_{29} / \mathrm{C}$ composite as an anode material for lithium-ion batteries. Int. J. Hydrog. Energy 41, 14807-14812 (2016).

23. Deng, $\mathrm{S}$. J. et al. $\mathrm{Ti}_{2} \mathrm{Nb}_{10} \mathrm{O}_{29-\mathrm{x}}$ mesoporous microspheres as promising anode materials for high-performance lithium-ion batteries. J. Power Sources 362, 250-257 (2017).

24. Zhang, X. Y. et al. Oxygen Defect modulated titanium niobium oxide on graphene arrays: an open-door for high-performance $1.4 \mathrm{~V}$ symmetric supercapacitor in acidic aqueous electrolyte. Adv. Funct. Mater. 28, 1805618 (2018).

25. Han, J. T., Huang, Y. H. \& Goodenough, J. B. New anode framework for rechargeable lithium batteries. Chem. Mater. 23, 2027-2029 (2011).

26. Yao, Z. J. et al. Enhancing ultrafast lithium ion storage of $\mathrm{Li}_{4} \mathrm{Ti}_{5} \mathrm{O}_{12}$ by tailored $\mathrm{TiC} / \mathrm{C}$ core/shell skeleton plus mitrogen doping. Adv. Funct. Mater. 28, 1802756 (2018).

27. Yao, Z. J. et al. Superior high-rate lithium-ion storage on $\mathrm{Ti}_{2} \mathrm{Nb}_{10} \mathrm{O}_{29}$ arrays via synergistic $\mathrm{TiC} / \mathrm{C}$ skeleton and $\mathrm{N}$-doped carbon shell. Nano Energy $\mathbf{5 4}$, 304-312 (2018).

28. Farges, F., Brown, G. E. \& Rehr, J. J. Ti K-edge XANES studies of Ti coordination and disorder in oxide compounds: comparison between theory and experiment. Phys. Rev. B 56, 1809 (1997).

29. Berthereau, A. et al. Determination of local geometries around tellurium in $\mathrm{TeO}_{2}-\mathrm{Nb}_{2} \mathrm{O}_{5}$ and $\mathrm{TeO}_{2}-\mathrm{Al}_{2} \mathrm{O}_{3}$ oxide glasses by XANES and EXAFS: investigation of electronic properties of evidenced oxygen clusters by $\mathrm{Ab}$ initio calculations. J. Solid State Chem. 126, 143-151 (1996).

30. Zang, Y. P. et al. Tuning orbital orientation endows molybdenum disulfide with exceptional alkaline hydrogen evolution capability. Nat. Commun. 10, 1217 (2019)

31. $\mathrm{Wu}, \mathrm{Y}$. S. et al. Electron density modulation of $\mathrm{NiCo}_{2} \mathrm{~S}_{4}$ nanowires by nitrogen incorporation for highly efficient hydrogen evolution catalysis. Nat. Commun. 9, 1425 (2018).

32. Guo, B. K. et al. A long-life lithium-ion battery with a highly porous $\mathrm{TiNb}_{2} \mathrm{O}_{7}$ anode for large-scale electrical energy storage. Energy Environ. Sci. 7, 2220-2226 (2014)

33. Lin, C. F. et al. Defective $\mathrm{Ti}_{2} \mathrm{Nb}_{10} \mathrm{O}_{271}$ : an advanced anode material for lithium-ion batteries. Sci. Rep. 5, 17836 (2015).

34. Zhu, H. et al. Hydration and thermal expansion in anatase nanoparticles. Adv. Mater. 28, 6894-6899 (2016)

35. Liu, Q. et al. Approaching the capacity limit of lithium cobalt oxide in lithium ion batteries via lanthanum and aluminium doping. Nat. Energy 3, 936-943 (2018).

36. Zhu. H. et al. In situ probing multiple-scale structures of energy materials for Li-ion batteries. Small Methods https://doi.org/10.1002/smtd.201900223.

37. Deng, S. J. et al. Synergistic doping and intercalation: realizing deep phase modulation on $\mathrm{MoS}_{2}$ arrays for high-efficiency hydrogen evolution reaction. Angew. Chem. Int. Ed. 58, 16289-16296 (2019).

38. Zhang, Y. et al. Multiscale graphene-based materials for applications in sodium ion batteries. Adv. Energy Mater. 9, 1803342 (2019).

39. Bellafont, N. P., Viñes, F., Hieringer, W. \& Illas, F. Predicting core level binding energies shifts: suitability of the projector augmented wave approach as implemented in VASP. J. Comput. Chem. 38, 518-522 (2017).

40. Chiu, C. C., Genest, A., Borgna, A. \& Rösch, N. Hydrodeoxygenation of guaiacol over Ru(0001): a DFT study. ACS Catal. 4, 4178-4188 (2014).

41. Peng, H. W. \& Perdew, P. P. Rehabilitation of the perdew-burke-ernzerhof generalized gradient approximation for layered materials. Phys. Rev. B 95, 081105 (2017).

\section{Acknowledgements}

This work is supported by National Natural Science Foundation of China (Grant No. 51772272 and 51728204), National youth talent support program of China, Natural Science Funds for Distinguished Young Scholar of Zhejiang Province (Grant No. LR20E020001), National youth talent support program of China, Natural Science Funds for Distinguished Young Scholar of Zhejiang Province (Grant No. LR20E020001), 
Fundamental Research Funds for the Central Universities (Grant No. 2018QNA4011), Qianjiang Talents Plan D (QJD1602029), Startup Foundation for Hundred-Talent Program of Zhejiang University, Key Research and Development Program of Hainan Province (ZDYF2017166). This study was partially sponsored by the project of Fundamental Investigation of Phase Transformative Materials for Energy Application (Project No. 9610399) supported by the City University of Hong Kong and was partially supported by the Shenzhen Science and Technology Innovation Committee (Grant No. R-IND14701). We also appreciate the Photoemission Endstations (BL10B) of Hefei National Synchrotron Radiation Laboratory (NSRL), soft x-ray microscope at beam BL07W in NSRL, 4W7A beamline of the Beijing Synchrotron Radiation Facility (BSRF) and BL14W1 beamline of the Shanghai Synchrotron Radiation Facility (SSRF) for help in XANES and EXAFS characterizations. This research also used resources of the Advanced Photon Source, the US Department of Energy (DOE) Office of Science User Facility operated for the DOE Office of Science by Argonne National Laboratory under Contract No. DEAC02-06CH11357.

\section{Author contributions}

S.J.D., X.H.X., Q.L. and L.G. designed and supervised the project. S.J.D., H.Z. and G.Z.W conducted the project and contributed equally to this work. M.L. performed the XANES, EXAFS, and XPS measurements. S.H.S., Y.Z., B.L., G.X.P., Q.Q.X., X.L.W. and J.P.T. helped analyze the data. Q.H.Z. performed HRTEM. L.Y., C.Z.A. and S.W.L. performed DFT calculation. G.Z.W. helped synthesize samples. X.H.X., S.J.D., L.G. and Q.L. wrote and revised the paper.

\section{Competing interests}

The authors declare no competing interests.

\section{Additional information}

Supplementary information is available for this paper at https://doi.org/10.1038/s41467019-13945-1.

Correspondence and requests for materials should be addressed to L.G., Q.L. or X.X.

Peer review information Nature Communications thanks the anonymous reviewer(s) for their contribution to the peer review of this work.

Reprints and permission information is available at http://www.nature.com/reprints

Publisher's note Springer Nature remains neutral with regard to jurisdictional claims in published maps and institutional affiliations.

(c) (i) Open Access This article is licensed under a Creative Commons Attribution 4.0 International License, which permits use, sharing adaptation, distribution and reproduction in any medium or format, as long as you give appropriate credit to the original author(s) and the source, provide a link to the Creative Commons license, and indicate if changes were made. The images or other third party material in this article are included in the article's Creative Commons license, unless indicated otherwise in a credit line to the material. If material is not included in the article's Creative Commons license and your intended use is not permitted by statutory regulation or exceeds the permitted use, you will need to obtain permission directly from the copyright holder. To view a copy of this license, visit http://creativecommons.org/ licenses/by/4.0/.

(c) The Author(s) 2020 